\title{
O jogo dominó das 4cores: estudo sobre análise de protocolos
}

\author{
Lino de Macedo \\ Universidade de São Paulo - SP \\ Ana Lucia Petty \\ Universidade de São Paulo - SP \\ Gisele E. de Carvalho \\ Universidade de São Paulo - SP \\ Maria Thereza C. C. de Souza \\ Universidade de São Paulo - SP
}

\section{Resumo}

Esta pesquisa teve como objetivo analisar protocolos com registros do jogo Dominó das 4cores, para investigar diferentes formas de resolução propostas por 46 crianças, de idade entre sete e onze anos, que frequentavam atividades em um contexto de oficinas de jogos. Para a coleta de dados, os participantes resolveram situações-problema e as informações foram obtidas por meio da análise dos protocolos. A partir desta análise, foi possível caracterizar os modos de resolução em termos de respeito às regras, estratégias, erros e acertos. Os resultados indicaram que: 1 - os sujeitos jogaram de acordo com as regras; 2- atuaram regularmente por ensaio-e-erro; 3- houve alta frequência de erros percebidos a posteriori. Como consequência, foi possível propor intervenções para desencadear a observação das ações e a construção de novos procedimentos e atitudes favoráveis ao jogar, assim como ao desenvolvimento e à aprendizagem escolar.

Palavras-chave: Jogos, procedimentos, aprendizagem escolar;

\section{The 4 colours game: a study about protocol analysis}

\begin{abstract}
In this study we aim at analysing protocols of a game named 4 Colours Domino, in order to investigate different forms of solution proposed by 46 participants aged 7 to 11 years old. All of them took part in a playing games context. To collect data children faced problem-solving situations and the protocols were analysed. Considering this analysis, it was possible to characterize the different modes of solution in terms of rules, strategies, success and mistakes. Results showed that: (a) participants played according to the rules; (b) in general, they acted by chance; (c) most of them noticed the mistakes only after they were made. As a consequence, it was possible to define adequate interventions to help students observe their actions and build up new procedures to surpass mistakes, contributing to the development and learning processes.
\end{abstract}

Keywords: Games, procedures, school learning

\section{El juego dominó de los 4 colores: estudio sobre análisis de protocolos}

\section{Resumen}

Esta investigación tuvo como objetivo analizar protocolos con registros del juego Dominó de los 4 colores, para investigar diferentes formas de resolución propuestas por 46 niños, de edad entre siete y once años, que frecuentaban actividades en un contexto de talleres de juegos. Para la recolecta de datos, los participantes solucionaron situaciones-problema y las informaciones fueron obtenidas por intermedio del análisis de los protocolos. Tras este análisis, fue posible caracterizar los modos de resolución en términos de respeto a las reglas, estrategias, errores y aciertos. Los resultados indicaron que: 1- los sujetos jugaron de acuerdo con las reglas; 2- actuaron regularmente por ensayo-y-error; 3- hubo alta frecuencia de erros percibidos a posteriori. Como consecuencia, fue posible proponer intervenciones para desencadenar la observación de las acciones y la construcción de nuevos procedimientos y actitudes favorables al jugar, así como al desarrollo y al aprendizaje escolar.

Palabras-clave: Juegos, procedimientos, aprendizaje escolar 


\section{Introdução}

Aprender a observar e interpretar registros em busca de indicadores qualitativos sobre os procedimentos utilizados tem sido um dos principais desafios enfrentados pelos profissionais que atuam na Educação (Estrela, 1984; Pereira, 1999), pois medir e classificar resultados são recursos insuficientes quando se pretende intervir no sentido de os alunos compreenderem problemas e superarem suas dificuldades. Neste sentido, reduzir a avaliação a um resultado numérico parece pouco eficaz quando o objetivo é contribuir para os alunos perceberem os próprios erros e corrigi-los (Hadji, 1993; Perrenoud, 1999).

Diversos autores, entre eles Macedo, Petty e Passos (1997, 2000, 2005), Meirieu (1998), Murcia (2002) e Pozo (1994), propõem formas de solucionar ou, ao menos, amenizar esta situação por meio de jogos. Este talvez seja um dos motivos pelos quais se constata o uso crescente destes recursos em contextos de situações-problema, sendo eles utilizados na avaliação e intervenção em atendimentos clínicos e no trabalho no ambiente escolar. Outras contribuições do jogar para o desenvolvimento e a aprendizagem também podem ser conferidas em pesquisas como as de Brenelli (1996, 2002), Zaia (1996, 2007), Souza, Petty e cols. (2002), Zuben (2003), Rossetti e Missawa (2008), Dias (2009) e Saravalli e cols. (2009). Estes estudos indicam que a ação de jogar e o contexto lúdico são fundamentais para intervir positivamente nos processos de desenvolvimento e aprendizagem de crianças com dificuldades escolares e inadequação de comportamento.

Esta análise, circunscrita ao jogo Dominó das 4Cores, poderá servir como mais uma ilustração do valor do uso de jogos para o campo pedagógico ou psicopedagógico. Ele faz parte de uma estrutura de jogos denominada 4 cores (Gúzman, 1991; Macedo, Petty e Passos, 1997), caracterizada pelo desafio de pintar uma figura com quatro cores de modo que cores iguais não sejam adjacentes, ou seja, o jogador deve unir peças para formar um quadrado que não pode ter cores iguais dispostas em contiguidade espacial.

No tocante ao campo de estudos sobre jogos, a teoria de Piaget traz importantes contribuições para fundamentar pesquisas desta natureza. Em uma de suas obras, intitulada "A Formação do Símbolo na Criança" (1978), o autor apresentou uma classificação dos jogos em três grandes estruturas: exercício, símbolo e regras. Jogos de regras implicam adequação à realidade e aprendizagem sobre as relações sociais, e requerem combinações intelectuais reguladas por regras e pela consideração do outro, de modo competitivo. O autor afirma que a construção do conhecimento é um processo que supõe a relação sujeito-objeto em um contexto em que ações significativas constituem condição para o sujeito construir novas estruturas. Inicialmente estas ações são concretas e observáveis, envolvendo movimento e manipulações; mas no decorrer do desenvolvimento a criança vai gradualmente estabelecendo relações que exigem menos ação física, já que estas relações também podem ser executadas mentalmente. A capacidade de pensar, levantar hipóteses e definir metas passa a ser uma ação mental possível, o que permite agir com mais intencionalidade e planejamento bem como coordenar diferentes ações e considerar outros pontos de vista. À medida que as regras vão sendo compreendidas como reguladores sociais torna-se possível construir formas de jogar mais bem-sucedidas, subordinadas às regras e articuladas com as coordenações que o sujeito criou. Tais ações favorecem o desenvolvimento das interações sociais e também de atitudes cooperativas (Piaget, 1994), sendo imprescindível fazer uso de habilidades como atenção, organização e autocontrole (Petty, \& Souza, 2012), tudo isso constituindo as bases fundamentais para a construção da autonomia e respeito mútuo. No campo do desenvolvimento infantil, sabe-se que jogos de regras cumprem um papel importante no estudo do comportamento de crianças no tocante ao desenvolvimento cognitivo, social e afetivo (Rossetti, \& Ortega, 2012). É interessante analisar de que modo as crianças praticam as regras, e também como compreendem sua função e constroem estratégias.

Atender crianças com dificuldades de aprendizagem em contextos de avaliação e intervenção com jogos tem apresentado resultados favoráveis no que se refere à contribuição para construírem novos procedimentos e modificarem atitudes desfavoráveis ao desenvolvimento e à aprendizagem escolar (Petty, \& Souza, 2012; Folquitto, 2013). Para acompanhar os progressos, intervir com precisão e compreender as necessidades de cada participante, faz-se necessário elaborar protocolos de observação em que suas ações sejam registradas de modo a permitir a análise de possíveis indicadores dos procedimentos realizados (Macedo, Petty, Carvalho, \& Carracedo, 2004; Macedo, Carvalho, \& Petty, 2009).

Há mais de duas décadas o Laboratório de Psicopedagogia (atualmente denominado Laboratório de Estudos sobre Desenvolvimento e Aprendizagem) do Instituto de Psicologia da Universidade de São Paulo vem realizando atendimentos e pesquisas que fornecem informações sobre o desenvolvimento infantil, especialmente sobre seu modo de enfrentar e resolver problemas em um contexto de jogos e desafios lógicos. Foi elaborado um programa de avaliação e intervenção baseado em uma metodologia do uso de jogos (Macedo, Petty, \& Passos, 2000) em que este é subdividido em quatro momentos: primeiro, as crianças aprendem regras e realizam propostas com diversas modalidades de jogos, sendo observadas e orientadas sobre como agir e explorar os materiais. Depois elas devem jogar diversas partidas para construir estratégias, e nesse período elas são questionadas sobre procedimentos e atitudes. O terceiro momento supõe a realização de situações-problema criadas a partir das situações vivenciadas no contexto do jogar, com o objetivo de monitorar os progressos e verificar eventuais mudanças nos procedimentos e estratégias, sendo necessário registrar em protocolos os diferentes modos de resolução. Por fim - e fundamentalmente - cada participante é estimulado a observar e estabelecer relações entre as atitudes e procedimentos construídos ao jogar com suas dificuldades, apropriando-se dos novos recursos desenvolvidos. Com isso, num processo 
que dura aproximadamente dois anos, as crianças apresentam melhora significativa nos aspectos identificados como negativos para o desenvolvimento e a aprendizagem. O objetivo não é que elas se tornem bons jogadores, mas que superem dificuldades de aprendizagem e modifiquem atitudes inadequadas, conscientizando-se dos novos recursos e competências e fazendo uso desses recursos em diferentes contextos, seja na escola seja no seu cotidiano. Neste processo, os protocolos de registro também têm uma função fundamental: servem como referência de comparação entre o que era feito e o que mudou - o que permite visualizar com mais objetividade e clareza os erros e mudanças de estratégias. Um bom exemplo do uso de protocolos como forma de observação de procedimentos é a tese de doutorado de Torres (2001). A pesquisadora coletou seus dados em nosso laboratório realizando atendimento para adolescentes com dificuldades de aprendizagem com jogos e situações-problema. Ao final de dois anos de um estudo longitudinal, baseado em observações e análise de registros, concluiu que todos os participantes haviam progredido em três âmbitos: nível de pensamento, campo pedagógico (conteúdos de Matemática e Linguagem) e expressão de atitudes (autonomia e socialização).

O presente estudo é uma forma de colaborar com os diversos autores que destacam a importância do jogar para fornecer dados aos profissionais que fazem uso deste recurso para atender crianças. Neste caso, realizamos uma pesquisa com análise qualitativa de protocolos com registros do jogo Dominó das 4Cores, visando conhecer as diferentes formas de resolução propostas por crianças. Assim, foi possível: 1- observar a realização de desafios em situações individuais; 2- registrar procedimentos de jogo no que se refere a regras, estratégias, soluções e erros; 3- caracterizar ou qualificar estas ações em diferentes níveis de desempenho; 4- construir formas de intervenção para instigar a criança a observar suas ações com vista a produzir mudanças qualitativas ao jogar; e 5- discutir possíveis contribuições e implicações do jogar, de forma a favorecer a construção de novos procedimentos e atitudes, o que, em última instância, promove o desenvolvimento e a aprendizagem escolar.

\section{Método}

O Dominó das 4Cores tem sido utilizado regularmente em nosso laboratório nas oficinas que desenvolvemos para crianças, principalmente porque permite uma rica análise dos procedimentos construídos para sua resolução, além de valorizar a elaboração e proposição de situações-problema, pois amplia a coleta de informações sobre a forma de pensar e de enfrentar desafios expressos por elas. Com isso, aprofundamos os conhecimentos sobre as contribuições deste jogo, uma vez que buscamos desenvolver critérios para observar e, mais que isso, analisar qualitativamente os registros produzidos no contexto desta investigação para propor intervenções.
Cumpre ressaltar que, embora o procedimento de coleta e análise de dados seja qualitativo, os resultados foram apresentados também de forma quantitativa (frequência).

\section{Material}

O Dominó das 4Cores compõe-se de dezoito peças, que devem ser posicionadas de modo a formarem um quadrado $(18 \times 18 \mathrm{~cm})$ em que as cores iguais não podem ser vizinhas, nem mesmo nos cantos (ângulos). O material originalmente concebido é feito de peças feitas de madeira, as quais são assim organizadas: seis pequenas $(3 \times 3 \mathrm{~cm})$ - sendo três azuis, duas vermelhas e uma amarela; seis médias, de $6 \times 3 \mathrm{~cm}$ - portanto cada uma equivale ao dobro das pequenas -, sendo duas azuis, duas vermelhas e duas verdes; e seis grandes $(9 \times 3 \mathrm{~cm})$, cada uma equivalendo, assim, ao triplo das pequenas, sendo duas azuis, duas amarelas e duas verdes. Na figura 1 apresentamos uma solução possível.

\section{Sujeitos e local}

Participaram desta pesquisa 46 crianças, de idade entre sete e onze anos, que frequentam as oficinas de jogos do Laboratório da Universidade X, num projeto denominado "Jogos de regras e aprendizagem escolar: apoio psicopedagógico para alunos da Escola Fundamental".

Figura 1: uma solução do Dominó das 4Cores

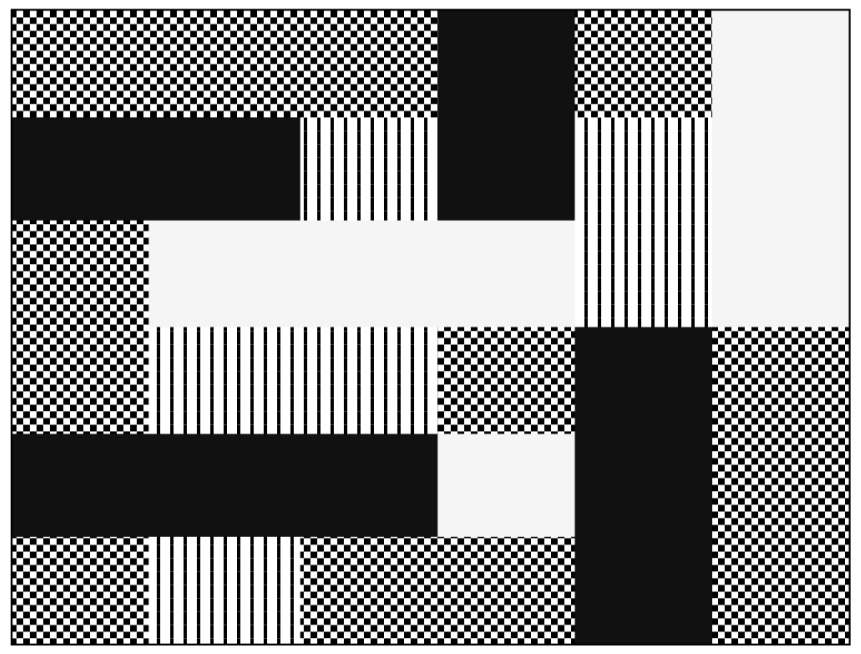

Legenda da Figura 1.

\begin{tabular}{|r|l|}
\hline & $=$ amarelo \\
& $=$ verde \\
& \\
20 & $=$ azul
\end{tabular}




\section{Procedimentos para a coleta e análise dos dados}

Para realizar a coleta de dados, propusemos uma situação-problema, ou seja, um desafio para as crianças. Com isso obtivemos informações por meio da análise do material, observando uma sequência de atividades que são descritas a seguir.

\section{Antes da situação-problema: conhecer material, objetivo do jogo e regras}

Distribuímos um jogo para cada criança e solicitamos que observassem o material. Para orientá-las, fomos fazendo perguntas sobre quantas peças compunham o jogo, de que cores eram, quantas eram azuis, verdes, brancas ou amarelas, quais os tamanhos (quantas pequenas, médias, grandes) e de que cores eram. Estas perguntas foram elaboradas com o objetivo de contribuir para estimular a observação, comparação e análise das peças. Em geral, constatar as características do material não garante o bom desempenho do jogador, podendo ajudar apenas num primeiro contato portanto é condição necessária, mas não suficiente. Além disso, considerando-se outras experiências que já tivemos com jogos, não valorizar este procedimento empobrece a atividade. Após estas atividades de exploração do material, apresentamos as regras e propusemos que os participantes fizessem tentativas de montagem do quadrado, esclarecendo dúvidas relativas às regras para sua construção.

Em síntese, duas ações - aprender as regras e esclarecer dúvidas - são fundamentais para o jogo acontecer, por isso é muito importante ter certeza de que cada um compreendeu os procedimentos de jogo para possibilitar realizar uma avaliação de seu desempenho como jogador. Com este procedimento, evitamos confundir aprendizagem de regras com construção de estratégias.

\section{Situação-problema: registro de soluções}

O objetivo da atividade foi montar dois quadrados com o material de madeira e fazer dois registros, correspondentes às soluções construídas. Para tanto, cada criança recebeu uma matriz quadriculada (grade) com um quadrado correspondente ao que montaria, só que em tamanho menor. Sua tarefa consistia em pintar as duas soluções, uma por vez, quando sua construção fosse finalizada (de acordo com as regras do jogo), sendo que, na segunda vez, deveria construir uma solução diferente da anterior. Este momento permitiu obter diversos registros com as tentativas de resolução do quadrado. Por meio das duas soluções produzidas, foi possível analisar aspectos como a quantidade de erros não percebidos, os tipos de erros que ocorreram (por exemplo: somente nos cantos, entre peças azuis, entre muitas peças simultaneamente) e as variações no posicionamento das peças.

Estes protocolos também possibilitaram observar o trabalho de correspondência que a criança teve ao realizar a tarefa: montar com o material de madeira e transpor a solução para o papel, tendo que, necessariamente, realizar uma cuidadosa contagem dos quadradinhos. Este desafio da pintura ainda consistiu em três exigências: coordenação motora, organização espacial e domínio do tamanho das peças. Se a criança não percebesse, por exemplo, que a peça grande equivalia a três quadradinhos, teria problemas para pintar sua solução; mas como a ideia não era dificultar a produção do registro, e sim, verificar como a criança lidava com este desafio, quando ficava muito difícil, um dos observadores a ajudava, não na montagem de uma solução, mas no momento do registro.

\section{Resultados e discussão}

Os resultados foram analisados sob dois aspectos: 1- quanto aos registros de soluções apresentados pelas crianças (pintados nas grades de registro); e 1- quanto à interpretação de protocolos gerados pelas crianças, a título de ilustração.

Propor situações com registro de solução constitui fonte de muitas informações para o observador. Os registros podem indicar as formas de pensamento dos jogadores que buscam resolver os desafios do jogo. No caso do Dominó das 4Cores, as análises podem tomar como parâmetros algumas perguntas, a saber: Que recortes podem ser realizados a partir das produções dos jogadores? O que é possível observar diretamente nas matrizes? O que podemos inferir a partir destas observações? Que erros as crianças percebem? Como montam soluções?

Para cada questão foram elaboradas categorias de análise, relativas aos tipos de erros observados, como se segue.

\section{QUESTÃO 1: O que aparece nos registros de soluções?}

Nos registros (matrizes pintadas) é possível identificar quatro tipos de solução, desde as que apresentam falhas e/ou erros produzidos até a solução correta:

- Tipo 1: erros não observados pelo jogador, ou seja, situações que constituem "ciladas" (cores iguais vizinhas pintadas como uma solução possível); na matriz não há vestígios de cores apagadas ou cores modificadas, e somente isso poderia confirmar que o jogador percebeu uma "cilada" e tentou mudar a solução proposta, no momento da pintura;

- Tipo 2: erros percebidos posteriormente à montagem: ao registrar uma solução (que pensava possível), o jogador constata uma "cilada" e não pinta a peça que o faria errar, mas também não consegue resolver o impasse e deixa a região em branco; utra possibilidade é observar indícios de que mudou alguma cor que já tinha pintado, na tentativa de resolver o problema; 
Tabela 1. Resultados da análise de protocolos quanto à questão 1.

\begin{tabular}{|c|c|c|c|c|}
\hline Tipo 1 & Tipo 2 & Tipo 3 & Tipo 4 & Total \\
\hline 11 & 22 & 02 & 11 & 46 \\
\hline
\end{tabular}

- Tipo 3: percepção de erro na pintura do registro: ao perceber este erro, o jogador para a pintura e refaz a matriz, anulando a proposta anterior;

- Tipo 4: antecipação de erros, na montagem com as peças: quando realiza seu registro, o jogador já conseguiu resolver eventuais "ciladas" enquanto construía uma solução com as próprias peças do jogo e não apresenta erros na matriz pintada.

A tabela 1 apresenta uma síntese dos resultados observados nos protocolos quanto às produções referentes à questão 1 , distribuídas pelos tipos acima descritos.

Como se pode observar, há uma alta frequência de erros do tipo 2, indicando que a maioria dos sujeitos consegue perceber seus erros a posteriori. Isto significa que somente depois de pintar uma solução esta é percebida como incorreta e há tentativas de mudar a peça colocada. Com esta informação, podemos perceber quão difícil ainda é, para algumas crianças, manusear as peças e conhecer as regras. Somente com a prática e as vivências de real insucesso é que elas vão modificando esta conduta, visando prevenir erros. No caso do tipo 3, verificamos que praticamente nenhuma criança preferiu anular a solução registrada, mesmo tendo sido observados erros, ou seja, peças da mesma cor colocadas juntas. Este procedimento é relativamente comum quando se trata de pintar matrizes, provavelmente pelo fato de as crianças não quererem começar uma nova pintura, já que este tipo de registro dá bastante trabalho e representa, em si, um desafio.

\section{QUESTÃO 2: Quantos erros são produzidos?}

Neste caso, pode-se contar a quantidade de "ciladas" produzidas, visando verificar se são muitas, poucas ou inexistentes. Vejamos os tipos:

- Tipo 1: muitas "ciladas" (> ou =4): no jogo existem ao todo 18 peças; se uma solução apresentar mais que três "ciladas", será considerada como tendo muitas;

- Tipo 2: poucas "ciladas" (< ou =3): como consequência da proposta anterior, as soluções com menos que três "ciladas", estão serão consideradas como poucas;

- Tipo 3: nenhuma "cilada".

A tabela 2 apresenta uma síntese dos resultados observados nos protocolos quanto às produções referentes à questão 2 , distribuídas nos tipos acima descritos.

Tabela 2. Resultados da análise de protocolos quanto à questão 2.

\begin{tabular}{|c|c|c|c|}
\hline Tipo $\mathbf{1}$ & Tipo $\mathbf{2}$ & Tipo $\mathbf{3}$ & Total \\
\hline 08 & 26 & 12 & 46 \\
\hline
\end{tabular}

Nesta tabela observa-se um alto índice de frequência dos erros do tipo 2. Isto significa que os sujeitos, embora tenham apresentado registros com ciladas, conseguiram evitar um número excessivo delas, ou seja, ao todo não foram mais do que três por matriz. Este resultado é um interessante indicador de que as crianças compreenderam que ciladas deveriam ser evitadas. Mesmo não tendo sido bem-sucedidos em sua totalidade, devemos considerar que crianças desta faixa etária ainda não conseguem ter um olhar amplo sobre a totalidade espacial deste material, o que regularmente gera tais erros.

\section{QUESTÃO 3: Que tipo de "ciladas" aparecem nos registros?}

Uma questão importante é analisar a qualidade dos erros produzidos, ou seja, se os erros são facilmente perceptíveis ou se são menos perceptíveis. Também é interessante analisar quais cores estão em "cilada":

- Tipo 1: erros facilmente percebidos: estes erros consistem numa adjacência grande entre as peças, de modo que vizinhanças de peças da mesma cor ficam encostadas entre si, havendo uma linha entre as cores iguais;

- Tipo 2: erros menos fáceis de serem percebidos: estes erros constituem encontros de cores somente nos ângulos, ou seja, os "bicos" de peças de cor igual estão encostados, o que nem sempre é observado pelos jogadores, especialmente nas primeiras tentativas de montagem de uma solução;

- Tipo 3: "ciladas" com qualquer cor: podemos analisar se as "ciladas" são produzidas com todas as cores, indistintamente, ou se há uma cor em particular que é motivo da "cilada";

- Tipo 4: "ciladas" somente com as peças azuis: por serem algumas peças em maior número e ocuparem mais área que as demais peças, em geral as "ciladas" com peças azuis são as últimas a serem solucionadas pelos jogadores, ou seja, são as peças que "sobram" sem encaixe.

Tabela 3. Resultados da análise de protocolos quanto à questão 3.

\begin{tabular}{|c|c|c|c|c|}
\hline Tipo 1 & Tipo 2 & Tipo 3 & Tipo 4 & Total \\
\hline 20 & 14 & 17 & 17 & 34 \\
\hline
\end{tabular}

A tabela 3 apresenta uma síntese dos resultados observados nos protocolos quanto às produções referentes à questão 3 , distribuídas nos tipos acima descritos. Cumpre destacar que, neste caso, há um total de 34 matrizes (ao invés de 46), por terem sido analisadas somente as matrizes com "ciladas".

Na tabela 3 é possível observar uma distribuição de frequências relativamente equitativa quanto aos tipos de ciladas que aparecem nos registros; no entanto a frequência mais baixa $(\mathrm{N}=14)$ refere-se ao tipo de erro menos perceptível, daí uma provável explicação para haver menos 
ocorrências de tentativas de mudança de cores registradas na matriz.

\section{QUESTÃO 4: Qual o tamanho e a cor das peças que ficam nas "ciladas"?}

É também interessante caracterizar as peças cuja colocação cause "incômodo". Observamos que, em geral, isso vai se modificando à medida que o jogador melhora sua performance ao jogar - o que se expressa em seus registros.

- Tipo 1: sobram peças de qualquer tamanho ou cor, sem serem pintadas no registro: muitas vezes as primeiras tentativas podem ter pouco sucesso, o que implica muitas "ciladas";

- Tipo 2: sobram peças azuis e verdes, de qualquer tamanho, sem serem pintadas: acontece que, além das azuis, a segunda maior área ocupada é das peças verdes; e frequentemente aparecem "ciladas" com as peças mencionadas;

- Tipo 3: sobram somente peças azuis pequenas: cumpre ressaltar que os registros quase completamente pintados apresentam "ciladas" exclusivamente com peças azuis e pequenas, indicando que o jogador está prestes a solucionar, com sucesso, o desafio.

A tabela 4 apresenta uma síntese dos resultados observados nos protocolos quanto às produções referentes à questão 4, distribuídas nos tipos descritos. Observe-se, com relação às informações sobre as peças que restaram fora das matrizes, que se teve um total de 13 casos, daí o número inferior a 46 novamente.

Tabela 4. Resultados da análise de protocolos quanto à questão 4.

\begin{tabular}{|c|c|c|c|}
\hline Tipo 1 & Tipo 2 & Tipo 3 & Total \\
\hline 01 & 03 & 09 & 13 \\
\hline
\end{tabular}

Nesta tabela é possível observar que quase todas as crianças com dificuldade de definir um local para uma ou mais peças tiveram problema com a cor azul, daí o maior número de ocorrências do tipo 3 . As peças de cor azul geram maior deficuldade em colocar as peças para evitar ciladas, pois elas são em maior quantidade. Por exemplo, se comparadas as áreas de cada cor transformadas todas as peças em unidades (a maior valendo 3 e a média 2), é possível verificar que as azuis valem 13 , as verdes 10 , as amarelas 7 e as vermelhas seis unidades, o que explica a alta frequência de ciladas com as azuis.

A interpretação de protocolos gerados pelas crianças teve como objetivo ilustrar a aplicabilidade da análise qualitativa descrita, e para isso selecionamos três exemplos: Protocolo 1 (DIE), Protocolo 2 (JUL) e Protocolo 3 (BRU), respectivamente apresentados nas figuras 2 a 4 .

Em cada um desses protcolos serão destacados diversos aspectos que podem ser observados simultaneamente, relativos às questões (numeradas de 1 a 4), bem como os respectivos tipos de erros referentes a cada uma delas.

Legenda das Figuras 2 a 4

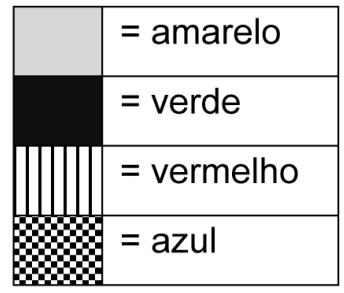

\section{Protocolo 1 (DIE; 7,2)}

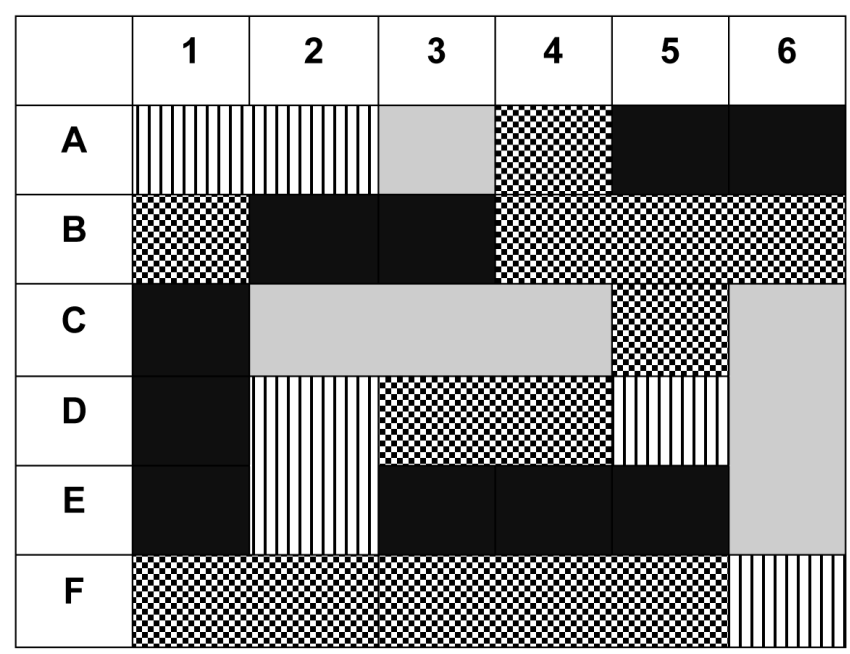

Figura 2. Protocolo 1 com solução de uma criança (DIE)

Nesta figura é possível identificar quatro características, descritas a seguir.

- A questão 1 tem como objetivo fazer uma análise de ordem geral, identificando se há ou não erros. Neste caso, a solução apresentada é do Tipo 1, ou seja, o jogador produziu erros sem percebê-los: ciladas A4-B4; B5-C5; C5-D4; B2-C1; F2-F3.

- A questão 2 visa analisar a quantidade de erros produzidos. Verifica-se a produção do tipo 1, sendo identificadas cinco ciladas: A4-B4; B5-C5; C5-D4; B2-C1; F2-F3.

- A questão 3 nos permite identificar todos os tipos de cilada: 1- o tipo 1, por ter três erros "facilmente observados": A4-B4; B5-C5; F2-F3; 2- o tipo 2, por apresentar dois "erros de bico": C5-D4; B2C1; 3- o tipo 3, por ter "cilada de qualquer cor": A4-B4; B5-C5; C5-D4; B2-C1; F2-F3; e 4- o tipo 4 , por também ter quatro "ciladas com peças azuis": A4-B4; B5-C5; C5-D4; F2-F3. 
Protocolo 2 (JUL; 9,1)

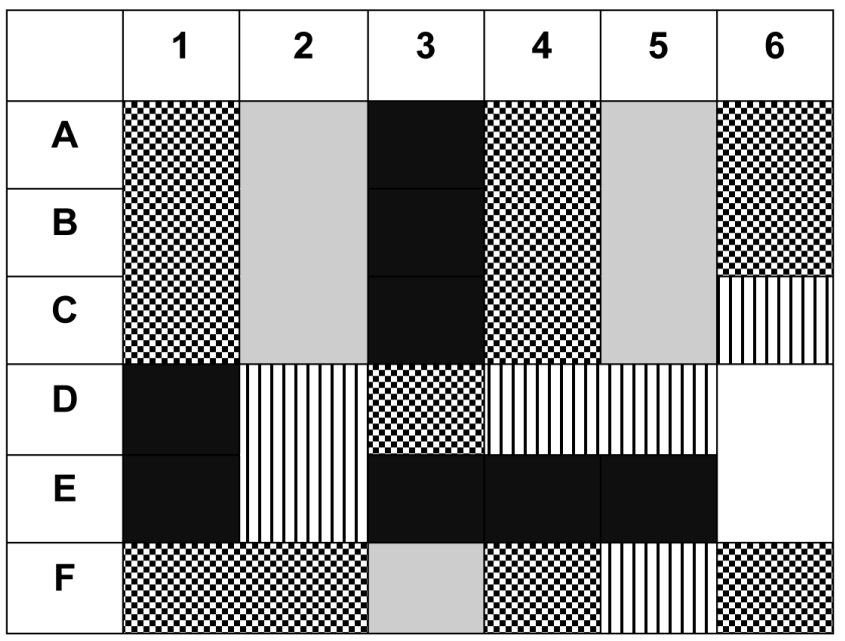

Figura 3. Protocolo 2 com solução de uma criança (JUL)

Nesta figura é possivel identificar quatro características, descritas a seguir.

- Quanto à questão 1 , aparecem na solução o tipo 1 - ciladas não percebidas C4-D3; C6-D5; e o tipo 2 - uma peça não é pintada, porque o jogador percebeu que seria uma cilada: D6-E6.

- Na questão 2 é possível identificar o tipo 2, pois aparecem somente duas ciladas: C4-D3; C6-D5.

- Na questão 3 verificamos solução do tipo 2, por apresentar dois "erros de bico": C4-D3; C6-D5

- Nesta figura aparecem características da questão 4 , ou seja, o jogador não pinta alguma peça, pois percebe seu erro antes de registrar a cor no protocolo. Neste caso, identificamos o tipo 1, pois sobra uma peça verde: D6-E6.

Protocolo 3 (BRU; 11,0)

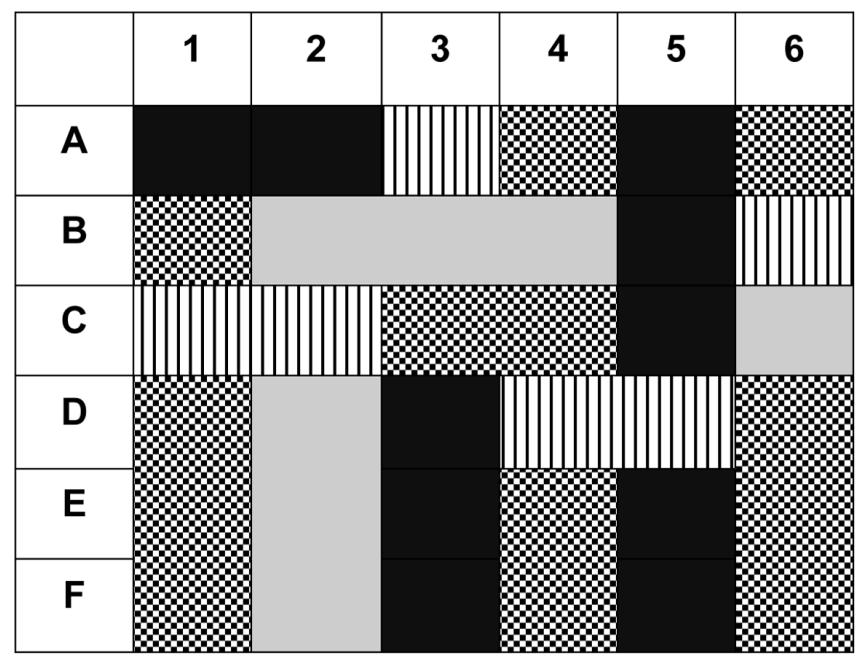

Figura 4. Protocolo 3 com solução de uma criança (BRU)
Nesta figura, é possível identificar três características, descritas a seguir.

- Quanto à questão 1, aparece na solução o tipo 3, que representa ausência de erros, indicando que o jogador conseguiu êxito na resolução.

- $\quad$ Na questão 2 é possível identificar o tipo 3, pois não são identificadas ciladas.

- Neste caso, não há ocorrência das questões 3 e 4 , por serem especificamente destinadas à análise de erros, e estes não ocorreram.

Esta pesquisa permitiu qualificar os níveis de desempenho com maior precisão, pois também pudemos identificar, nos protocolos, ilustrações ou indícios correspondentes aos conteúdos relativos ao jogo 4Cores no papel (Macedo, Petty e Passos, 1997; De Souza, Petty et al. 2002). Neste caso citado, foram analisados protocolos em que os jogadores pintavam uma matriz do jogo, seguindo as mesmas regras: não utilizar cores iguais em regiões adjacentes. Foram observados níveis de desempenho, análogos aos observados na presente pesquisa, referentes à construção de quadrados. Assim, também para a presente pesquisa os registros poderiam ser classificados, conforme propõem os autores, em três níveis:

NÍVEL 1 - a criança monta o quadrado sem planejar, colocando as peças aleatoriamente ou, quando muito, obedecendo às regras. Neste nível é possível, por sorte ou facilidade da proposta, montar corretamente o quadrado, mas isto não significa ter havido intencionalidade. As ações caracterizam-se pelo sincretismo e justaposição. Observa-se a ocorrência de muitos erros (ciladas) que não são percebidos nem geram conflito na criança, ou seja, peças adjacentes da mesma cor, como se não houvesse limites entre elas. Em alguns casos ela não consegue terminar de montar o quadrado sozinha e então desiste ou pede ajuda ao adulto, que atua como estímulo externo para fazê-la cumprir a proposta ou como aquele ao qual ela atribui poder de julgar seus acertos e erros.

NÍVEL 2 - a criança realiza ações ambivalentes e busca soluções por ensaio e erro. Há indícios de planejamento, mas sem garantia de sucesso na resolução como, por exemplo, separar todas as peças por cores (fora do tabuleiro) para melhor distribuí-las no espaço; porém esta ação não garante o sucesso na resolução, geralmente porque a criança considera somente parte do espaço planejado, comparando-o com algumas peças já colocadas, e assim perde a dimensão do todo. O erro é geralmente percebido depois de ser produzido: este passa a ser um problema para quem o produziu, já que se observam várias tentativas de evitá-lo, sendo a regra mantida como reguladora da ação. Nestes casos, muitas vezes a criança ainda recorre ao adulto, mas não como quem julga o erro, e sim, como quem pode ajudar a encontrar uma solução para o mesmo. 
NÍVEL 3 - a criança apresenta total compreensão do problema, justificando suas escolhas e coordenando várias regiões. O planejamento de suas ações tem um efeito mais eficaz que no nível anterior, já que ela consegue articular melhor as partes (peças já colocadas) em relação ao todo (espaço do tabuleiro), e assim previne seus erros. Quando percebe que vai cair em uma cilada, geralmente consegue evitá-la sozinha, ou então, se não o consegue, não coloca esta peça no tabuleiro. Raramente recorre ao adulto para resolver o desafio. Se isto ocorre, é mais para trocar ideias ou para tirar dúvidas relativas às estratégias, não às regras.

Como pudemos observar, tanto no 4Cores (Macedo,

Petty, \& Passos, 1997) como no Dominó das 4Cores há registros que indicam níveis qualitativamente diferentes e expressam diferentes procedimentos utilizados pelo jogador para resolver o desafio. Por esse motivo, no contexto das oficinas de jogos que desenvolvemos, valorizamos toda e qualquer produção como fonte valiosa de informações. Isto significa que, mesmo quando o sujeito não conseguiu realizar a tarefa proposta, suas ações (registradas nos protocolos) foram relevantes para informar o que ele realmente fez. Poder-se-ia então, erroneamente, concluir que nossa ênfase incide sobre o erro; no entanto cumpre esclarecer que de fato realizamos uma análise sobre a natureza do campo de observação do jogador, qualificando seu resultado e não nos restringindo exclusivamente à quantidade de erros produzidos ou ao resultado final (o que indicaria se se obteve sucesso ou se fracassou). Assim, a análise não deve ser compreendida como um olhar "pela falta", mas como um limite da situação em si (que impedia um olhar mais detalhado sobre os procedimentos "em ação"), ou como uma fonte de informações significativas para o processo de intervenção, posterior às atividades já executadas.

\section{Considerações finais}

O presente estudo permitiu concluir que a análise dos protocolos pode ser mais ou menos profunda, dependendo do objetivo e da possibilidade de cada profissional que irá coletar informações por meio deste recurso. Em sala de aula, o professor tem um tempo e um olhar limitados à quantidade de alunos presentes no momento do jogo. Tal situação não inviabiliza a proposta - embora sua disponibilidade seja mais ampla (atenção ao grupo) que focada (atenção a um aluno) - daí a contribuição do estudo dos protocolos, que permite levantar algumas hipóteses sobre o modo de pensar das crianças. Em outras palavras, seu desafio é diferente se o profissional está na clínica com um aluno ou com um pequeno grupo.

Nos casos em que seja possível observar a montagem e registro de soluções, pode-se ampliar a quantidade de informações e detalhar a qualidade de outros aspectos observáveis durante a ação de jogar propriamente dita. Por exemplo, é muito frutífero conversar com o aluno sobre suas decisões ainda na montagem, questionando suas ações. Pode-se também optar por numerar a sequência das peças que forem sendo pintadas, viabilizando a reconstituição da partida; ou ainda, é possível observar com mais precisão como o registro foi feito e como o indivíduo organizou a colocação das peças fazendo-se perguntas como se selecionou as cores, se evitou deixar "buracos" na montagem, se reservou uma cor, se repetiu cores, etc.

Ainda outra possibilidade de análise seria estudar os protocolos considerando-se a idade dos sujeitos que produzem registros. Nesta investigação preferimos não fazer este recorte, valorizamos exclusivamente os modos de procedimento e formas de resolução.

Assim, a partir das informações obtidas com esta pesquisa, podem ser propostas atividades e intervenções que possibilitem a modificação do que é insuficiente para vencer o desafio do jogo.

Situações como esta permitem à criança vivenciar a constatação de suas ações, tomar consciência de seu alcance e refletir sobre a mudança de estratégias e a busca de outras soluções como aspectos fundamentais para melhorar seu desempenho. Estas atitudes tornam-se cada vez mais significativas no processo de construção de conhecimentos, especialmente a partir do momento em que generaliza as ações realizadas ao jogar para outros contextos. Piaget (1978) (citado por Inheder,Garcia, \& Vonèche, 1978, p. 155) afirma:

Partamos de uma inovação qualquer do sujeito, que, a meu ver, resulta sempre de uma necessidade anterior... logo que atualizada, essa inovação constitui um novo esquema de procedimento, que, como todo esquema, tenderá a alimentar-se, aplicando-se a situações análogas. Mas há mais: essa generalização possível do esquema de procedimento confere ao sujeito um novo poder e o simples fato de ter conseguido inventar um procedimento para certas situações favorecerá, aos meus olhos, o êxito noutras.

Com esta citação, tomada de Piaget, pensamos que contribuímos para ajudar crianças a ampliar seu campo de observação sobre suas ações, e mais que isso, sobre as implicações destas em outras situações semelhantes, percebendo-se como construtores de seus próprios conhecimentos e desenvolvendo recursos para modificar os processos que as levaram a fracassar. Num primeiro momento, esta aprendizagem está muito próxima da situação de jogo, como se estivesse "colada" nela; mas depois a pretensão do trabalho é que as conquistas passem a ser propriedade de quem as construiu, porque foram interiorizadas, assimiladas, processadas e generalizadas para outros contextos, principalmente o contexto escolar.

\section{Referências}

Brenelli, R. P. (2002) Espaço lúdico e diagnóstico em dificuldades de aprendizagem: contribuição do jogo de regras. Em Sisto, F.F. (Org.). Dificuldades de aprendizagem no contexto psicopedagógico (2.ed, pp.167-189). Petrópolis, RJ: Vozes. 
Brenelli, R. P. (1996). Uma proposta psicopedagógica com jogos de regras. Em Sisto, F., Oliveira, G. C., Fini, L. D. T., Souza, M. T. C. C., \& Brenelli, R. P. (Orgs.). Atuação psicopedagógica e aprendizagem escolar. Petrópolis: Vozes.

Dias, L. P. (2009) A construção do conhecimento em crianças com dificuldades em matemática utilizando o jogo de regras mancala. Dissertação de Mestrado em Educação. Faculdade de Educação, Universidade Estadual de Campinas, Campinas.

Estrela, A. (1984). Teoria e prática de observação de classes. Lisboa: Porto Editora.

Folquitto, C. T. F. (2013). Desenvolvimento psicológico e estratégias de intervenção com crianças com diagnóstico de TDAH. Tese de Doutorado em Psicologia do Desenvolvimento Humano. Instituto de Psicologia da Universidade de São Paulo, São Paulo.

Gúzman, M. de. (1991). Contos com contas. Lisboa: Gradiva.

Hadji, C. (1993). A avaliação, as regras do jogo. Lisboa: Porto Editora.

Inhelder, B., Garcia, R. e Vonèche, J. (1978). Epistemologia genética e equilibração. Lisboa: Livros Horizonte

Macedo, L. de, Petty, A. L, \& Passos, N. C. (1997). 4Cores, Senha e Dominó - oficinas de jogos em uma perspectiva construtivista e psicopedagógica. São Paulo: Casa do Psicólogo.

Macedo, L., Petty, A. L., \& e Passos, N. C. (2000). Aprender com jogos e situações-problema. Porto Alegre: Artmed.

Macedo, L., Petty, A. L., Carvalho, G. E., \& Carracedo, V. (2004). Avaliação do desempenho de crianças e intervenção em um jogo de Senha. Psicologia Escolar e Educacional, 7 (2), 185-195.

Macedo, L., Petty, A. L., \& Passos, N. C. (2005). Os jogos e o lúdico na aprendizagem escolar. Porto Alegre: Artmed.

Macedo, L., Carvalho, G. E., \& Petty, A. L. (2009). Modos de resolução de Labirintos por alunos da Escola Fundamental. Psicologia Escolar e Educacional, 13 (1), 15-20.

Meirieu, P. (1998). Aprender... sim, mas como? Porto Alegre: Artmed.

Murcia, J. A. M. (2002). Aprendizagem através do jogo. Porto Alegre: Artmed.

Pereira, J. C. R. (1999). Análise de dados qualitativos. São Paulo: Edusp.

Perrenoud, P. (1999). Avaliação: entre duas lógicas. Porto Alegre: Artmed.

Petty, A. L., \& Souza, M. T. C. (2012). Executive Functions Development and Playing Games. US-China Education Review B, 9, 795-801.
Piaget, J. (1994). O juízo moral na criança. São Paulo: Summus. (Trabalho original publicado em 1932).

Piaget, J. (1978). A formação do símbolo na criança: imitação, jogo e sonho, imagem e representação. Rio de Janeiro: Zahar. (Trabalho original publicado em 1945).

Piaget, J. Em Inhelder, B., Garcia, R., \& Vonèche, J. (1978). Epistemologia genética e equilibração. Ed. Horizonte Universitário.

Pozo, J. I. (1994). A solução de problemas. Porto Alegre: Artmed.

Rossetti, C. B., \& Ortega, A. C. (2012). Cognição, afetividade e moralidade. Estudos segundo o referencial teórico de Jean Piaget. São Paulo: Casa do Psicólogo.

Rossetti, C. B., \& Missawa, D. D. (2008). Desempenho de crianças com e sem dificuldade de atenção no jogo Mancala. Arquivos brasileiros de psicologia, 60 (2), p. 60-74.

Saravalli, E. G., Monteiro, T. A., Tassinari, E. C. C., Souza, M. M. ; Bom, D. D. \& Guimaraes, T. (2009) A atualidade da teoria de Jean Piaget no trabalho junto a crianças com dificuldades de aprendizagem. Caderno de resumos do I Colóquio Internacional de Epistemologia e psicologia genéticas, Aprendizagem e Conhecimento em Construção, 1, 561-573. Marília: UNESP.

Souza, M. T. C. C., Petty, A. L., Carvalho, G. E., Passos, N. C., \& Carracedo, V. (2002). Assessing game activities: a study with Brazilian children. Em Retschitzki, J., \& Haddad-Zubel, R. (Orgs.). Step by Step. Suisse: Editions Universitaires Fribourg.

Torres, M. Z. (2001) Desenvolvimento de adolescentes e processos de aprendizagem em um contexto de oficinas de jogos. Tese de Doutorado em Psicologia do Desenvolvimento Humano, Instituto de Psicologia da Universidade de São Paulo, São Paulo.

Zaia, L. L. (1996) A solicitação de meio e a construção das estruturas operatórias em crianças com dificuldades de aprendizagem. Tese de Doutorado em Psicologia Educacional. Faculdade de Educação, Universidade Estadual de Campinas, Campinas.

Zaia, L. L. (2007) Aprendizagem e desenvolvimento: superando dificuldades. Aprender. Caderno de Filosofia e Psicologia da Educação, 5 (9), 17-36.

Zuben, R. B. (2003) A construção dialética no jogo de regras Traverse em alunos com queixas de dificuldades escolares. Dissertação de Mestrado em Educação, Faculdade de Educação. Universidade Estadual de Campinas, Campinas. 
Sobre os autores

Lino de Macedo (limacedo@me.com)

Professor Titular do Instituto de Psicologia da USP.

Ana Lucia Petty (anapetty@dialdata.com.br)

Mestre em Psicologia - Instituto de Psicologia da USP.

Gisele E. de Carvalho (gisele@scient.com.br)

Psicopedagoga,

Maria Thereza C. C. de Souza (mtdesouza@usp.br)

Professora Associada - Instituto de Psicologia da USP. 